\title{
Synthesis of AgNPs by Bacillus Cereus Bacteria and Their Antimicrobial Potential
}

\author{
Anuradha Prakash ${ }^{1}$, Seema Sharma ${ }^{2 *}$, Naheed Ahmad ${ }^{3}$, Ashok Ghosh ${ }^{4}$, Preety Sinha ${ }^{5}$ \\ ${ }^{1}$ Department of Zoology, A.N. College, Patna, India; ${ }^{2}$ Department of Physics, A.N. College, Patna, India; ${ }^{3}$ Department of Botany, \\ Patna University, Patna, India; ${ }^{4}$ Department of Environment and Water Management, A.N. College, Patna, India; ${ }^{5}$ Department of \\ Zoology, A.N. College, Patna, India. \\ Email: seema_sharma26@yahoo.com
}

Received December $26^{\text {th }}, 2010$; revised January $17^{\text {th }}, 2011$; accepted January $18^{\text {th }}, 2011$.

\begin{abstract}
In the present work silver nanoparticles (AgNPs) were synthesized extracellularly by bacteria Bacillus cereus collected from the riverine belt of Gangetic Plain of India. The microbes were isolated, screened and characterized by morphological and biochemical analyses. The silver resistant strain was exposed to different concentrations of silver salt (Ag$\mathrm{NO}_{3}$ ). UV-visible spectrum of the supernatant of cell culture showed absorbance peak of AgNPs at $\sim 435 \mathrm{~nm}$. The shape and size of AgNPs were ascertained by High Resolution Transmission Electron Micrography (HRTEM), X-ray diffraction (XRD) and Energy Dispersive spectroscopy (EDS). Average size of the synthesized AgNPs was found to be in the range of $10-30 \mathrm{~nm}$ with spherical shape. AgNPs were tested against antibacterial potential of some common human pathogens.
\end{abstract}

Keywords: AgNPs, XRD, HRTEM, Antimicrobial

\section{Introduction}

Nanotechnology has become the new arena for future technology which is mainly dependent on nanometals and semiconductors. Nanoparticles synthesized by the chemical processes had toxic effect hence there is a growing need to develop environment friendly, cost effective and conveniently reproducible green methods of nanoparticle synthesis. Diversity of microbes is immense and this can be exploited purposefully for synthesis and harvesting of different nanoparticles. A vast range of organic and inorganic materials exist as colloids and nanoparticles in soil, infiltration water and ground water. The cell wall of bacteria is chemically and structurally more complex to the surface of inorganic nanoparticles, and it can adapt itself with the change in the environment. Bioscience can be employed to explore medical sciences in fighting pathogens [1], artificial implants [2], targeted drug delivery [3] etc and understanding the role and applications of microorganisms for the remediation of toxic and radionuclide contaminated sites and antibacterial effects. Microorganisms that affect the reactivity and mobility of metals can be used for detoxification and remediation. Many organisms both prokaryotes and eukaryotes are known to produce many inorganic materials either intracellularly or extracellularly [4]. These specific characteristics of organisms particularly of microorganisms can be used in the synthesis of nanoparticles. Metals are present in the environment in trace amount which are used by the organisms for their metabolic activities. Microbes have the capacity to alter their environment by selective interaction with metals. The micro flora of unique ecological niches yields microbial diversity which can be exploited for various ends, including production of nanoparticles. Biosynthesized nanoparticles find utilization in the fields of bioremediation, biolabelling, biosensors and many more [5]. It is reported that stable silver nanoparticles can be synthesized with controlled size in suitable matrices such as micelles [6], organic small molecules or microbes, [7] linear polymers [8], mesoporous materials [9], dendritic polymers [10,11]. The large scale synthesis of silver nanomaterials suffers from issues such as polydispersity and stability, especially if the reduction is carried out in aqueous media. Therefore the extracellular biological synthesis of AgNPs can be an attractive and ecologically friendly alternative method for the large quantities because it offers the advantage of easy downstream processing. Moreover, bacteria are easy to handle and can be manipulated genetically without much difficulty. The capability of producing crystalline silver particles through microbes in nanosize, and with 
controlled morphology is the basis of using this biological method in the field of material science. Silver ions promote bone growth and kill surrounding bacteria. They are also reported to be nontoxic to human and most effective against bacteria, viruses and other eukaryotic micro-organisms at very low concentration and without any side effects [12]. As most of the bacteria have developed resistance to antibiotics, there is a need of an alternative antibacterial substance [13]. AgNPs have an important advantage over conventional antibiotics in that it kills all pathogenic microorganisms, and no organism has ever been reported to readily develop resistance to it [14]. The silver nanoparticles synthesized by microbes can be used in target oriented drug delivery, food industry, as an antiseptic in waste water treatment, in curing and detecting many diseases, in making electronic devices. In this work, microbes were selected randomly and after several experiments one of the strains identified as Bacillus cereus was selected for synthesis of AgNPs and which were found to be fairly dispersed and exhibited effective antimicrobial effect.

\section{Experimental Details}

\subsection{Culture and Isolation}

The soil samples were collected from different sites of the wetland area, rich in microfauna of North Bihar of India along the river Ganges. Serial dilutions nutrient agar plates were made and pure culture was isolated after the requisite period of incubation (Figure 1). The identification and characterization of the culture was performed on morphological and biochemical basis. One of the most resistant strain Bacillus cereus was selected for further experiment. It was grown in $250 \mathrm{ml} \mathrm{MGYP} \mathrm{(glu-}$ cose $1 \%$, malt extract $1 \%$, yeast extract $0.3 \%$, peptone $0.5 \%$ ) medium in $500 \mathrm{ml}$ Erlenmeyer flask. The flasks were incubated at $37.5^{\circ} \mathrm{C}$ on a rotary shaker set at 100 rpm for $24 \mathrm{~h}$.

\subsection{Synthesis of AgNPs}

$\mathrm{AgNO}_{3}$ was added to the innoculum and put on shaker for $24 \mathrm{~h}$. One of the set of culture was treated as control for the experiment (without the silver salt). $\mathrm{AgNO}_{3}$ was added in different concentration ranging from 50, 100, 500, 1000, 1500, $20000 \mathrm{ppm}$ respectively. After $24 \mathrm{~h}$, this culture was filtered through Whatman filter paper no. 1 (medium retention, flow rate and porosity which are frequently used for clarifying liquids in biological experiments) and the cell free supernatant was observed on UV-VIS spectrophotometer with wavelength range of 200-600nm. The absorbance maxima of supernatant was taken at different time intervals after adding $\mathrm{AgNO}_{3}$. The culture was then centrifuged at $5000 \mathrm{rpm}$ for 15 minutes to recover the synthesized nanoparticles in the aliquot and was washed with distilled water 3 - 4 times to avoid any interference of the media in the characterization of the nanoparticles. Then the nanoparticles were allowed to dry and made into fine powder for their characterization through X-ray diffraction, Electron Diffraction Spectroscopy and Transmission Electron Microscopy.

\subsection{Characterization of AgNPs}

\subsubsection{X- Ray Diffraction Analysis}

The X-ray Diffraction (XRD) measurements of dropcoated films of AgNPs on glass substrate were recorded in a wide range of Bragg angle $2 \theta$ at a scanning rate of $2^{\circ} \mathrm{min}^{-1}$ carried out on a Philips PW 1830 instrument that was operated at a voltage of $40 \mathrm{kV}$ and a current of 30 $\mathrm{mA}$ with $\mathrm{Cu} \mathrm{K} \alpha$ radiation $(\lambda=1.5405 \AA)$.

\subsubsection{TEM and Electron Diffraction Analysis}

High Resolution Transmission Electron Microscopy (HRTEM) was performed by TECHNAI G20-STWIN

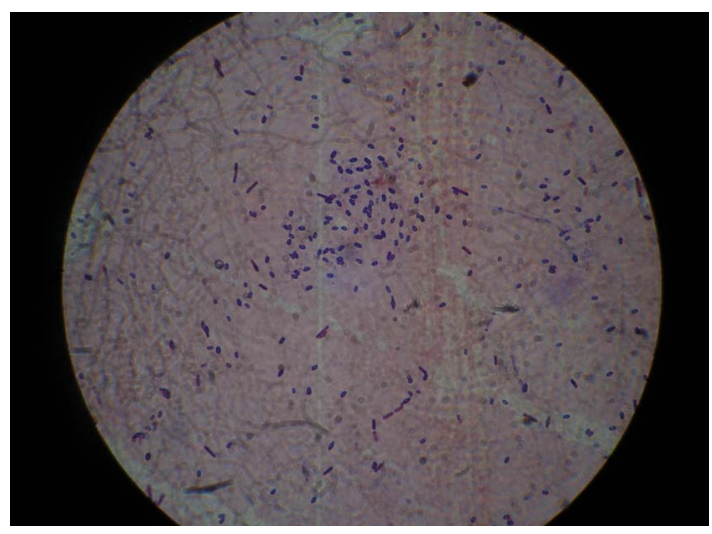

(a)

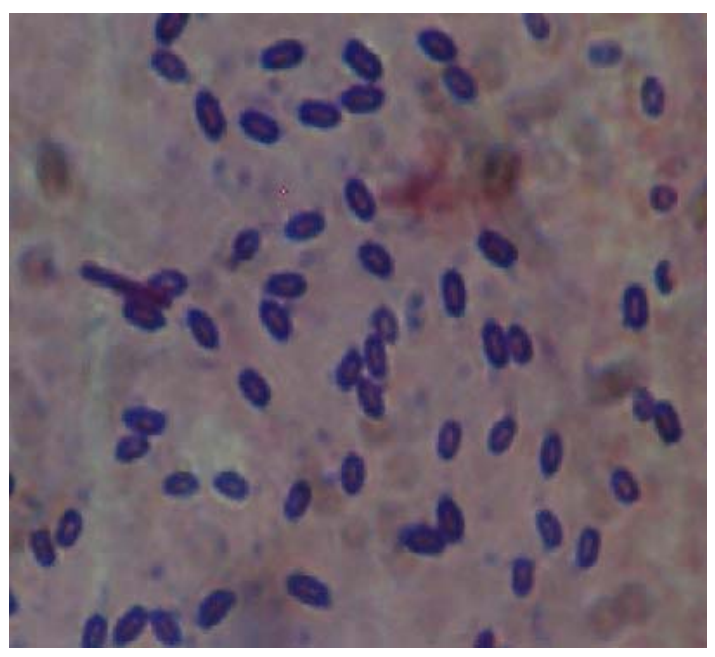

(b)

Figure 1. (a) Photograph of Bacillus cereus, the bacterial strain (100x magnification); (b) Photograph of Bacillus cereus (enlarged section). 
$(200 \mathrm{KV})$ machine with a line resolution $2.32\left(\right.$ in $\left.{ }^{\circ} \mathrm{A}\right)$. These images were taken by drop coating AgNPs on a carbon-coated copper grid. Energy Dispersive Absorption Spectroscopy photograph of AgNPs were carried out by the HRTEM equipment as mentioned above.

\subsection{Antimicrobial Activity Test for AgNPs}

After characterization of AgNPs their antibacterial effect was checked by disc diffusion or Kirby-Bauer method [15] on some common pathogens of human, E.coli and Streptococcus. This method is used to determine susceptible and resistant values [16].

\section{Results and Discussions}

\subsection{Synthesis of Silver Nanoparticles}

The results of this experiment i.e. extracellular synthesis of AgNPs were observed. The colour of the aliquot changed to deep orange after $24 \mathrm{~h}$ of agitation with $\mathrm{AgNO}_{3}$ (Figure 2 which further blackened in $72 \mathrm{~h}$. The black colour of the culture confirms the extracellular reduction of silver salt to AgNPs, however the bacterial strain treated with de-ionized water retained its original colour [17].

The absorbance scan taken by UV-VIS spectrophotometer showed a sharp plasmon peak at $\sim 435 \mathrm{~nm}$ (Figure not shown here), which confirms silver in nanoscale range. The size, shape and distribution of the nanomaterial affect the magnitude, peak and width of the spectrum band. As the colour of the culture changed in course of synthesis, its absorbance was recorded after regular intervals of time ( $24 \mathrm{~h}, 48 \mathrm{~h}, 72 \mathrm{~h}, 7$ days, 15 days and 30 days). The suspension was stored for about one month to observe the stability of the synthesized nanocrystallites. The silver nanocrystallites showed the peak at wavelength $430-440 \mathrm{~nm}$ range.

The mechanism for the synthesis of AgNPs by bacteria is not exactly deciphered till date but several possible ways of synthesis is being explained. The possible chemical reactions in the culture medium may be as follows:

$$
\begin{aligned}
& \mathrm{C}_{6} \mathrm{H}_{12} \mathrm{O}_{6} \rightarrow \mathrm{CH}_{3}-\mathrm{CO}-\mathrm{COOH} \\
& \text { (Glucose) } \quad \text { (Pyruvate) } \\
& \mathrm{NaHCO}_{3} \leftrightarrow \mathrm{Na}^{+} \quad+\quad \mathrm{HCO}_{3}^{-} \\
& \mathrm{HCO}_{3} \leftrightarrow \mathrm{OH}^{-}+\mathrm{CO}_{2} \\
& \mathrm{AgNO}_{3}+(\mathrm{OH})_{2} \rightarrow \mathrm{Ag}_{2} \mathrm{O}+\mathrm{H}_{2} \mathrm{O}+\mathrm{N}_{2} \\
& \mathrm{Ag}(\mathrm{OH})_{2} \rightarrow \mathrm{Ag}^{+} \downarrow+\mathrm{H}_{2} \mathrm{O}
\end{aligned}
$$

According to this concept, the transmembrane proton gradient effected by respiratory, adenosine trip- hosphatase, or bacteriorhodopsin activity is used to extrude $\mathrm{Na}^{+}$from the bacterial cells by means of a $\mathrm{Na}^{+}-\mathrm{H}^{+}$antiporter, resulting in the creation of an inwardly directed transmembrane $\mathrm{Na}^{+}$gradient. The chemical and electrical components of this gradient, either separately or in combination, can then be used.

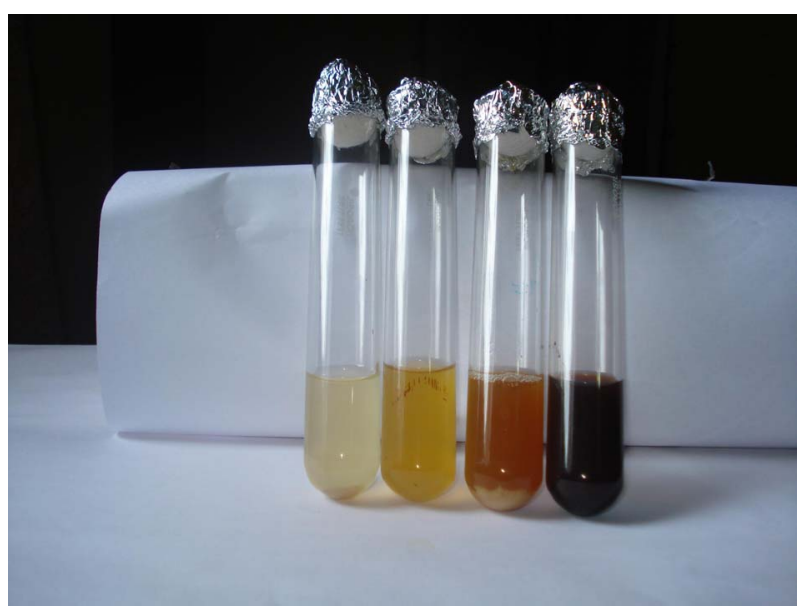

Figure 2. Photograph of change in colour of aliquot after addition of $\mathrm{AgNO}_{3}$ during different time period (from left to right): control, 24 hrs, 48 hrs and 72 hrs.

to drive the intracellular accumulation of nutrients. The proton gradient can power active transport indirectly, through the formation of sodium ion gradient in microorganism. In this reaction, Sodium symport (mentioned above) is an important process in cells and is used in sugar and amino acid uptake. ATP binding employ special substrate binding proteins, which are attached to membrane lipids on the external face of gram positive bacteria (B.cereus). A proton gradient can power active transport indirectly and most of the bacteria which have electrokinetic potential readily attract the cations and this probably acts as an initiator for the biosynthesis of nanoparticles [18].

The mechanism of transformation of oxidase to reductase and vice- versa due to change in $\mathrm{pH}$ might have taken place at two levels, at cell membrane level, or in the membrane of endoplasmic reticulum (Figure 3). Oxidase gets activated at lower $\mathrm{pH}$ whereas reductase gets activated at higher $\mathrm{pH}$ in the cell membrane $[19,20]$ which makes the molecular oxygen available for the transformation by the tautomerization of quinones. The molecular oxygen released by both processes is utilized in the conversion of silver to silver oxide. NADH serves as an electron carrier and transfers electron to receptors. The electrons flow from carriers with more negative reduction potential to those with more positive potentials and eventually combine with $\mathrm{O}_{2}$ and $\mathrm{H}_{2}$ to form water.

X-ray Diffraction (XRD) pattern (Figure 4) shows intense Bragg's reflections that can be indexed on the basis of the fcc structure of silver [19]. The XRD pattern thus obtained clearly shows [111], [200], [220] planes, and exhibit that the synthesized AgNPs by the Bacillus cereus were crystalline in nature. The values agree well with those reported for silver (face centric cubic) by the Joint Committee on Powder Diffraction Standards File No. 


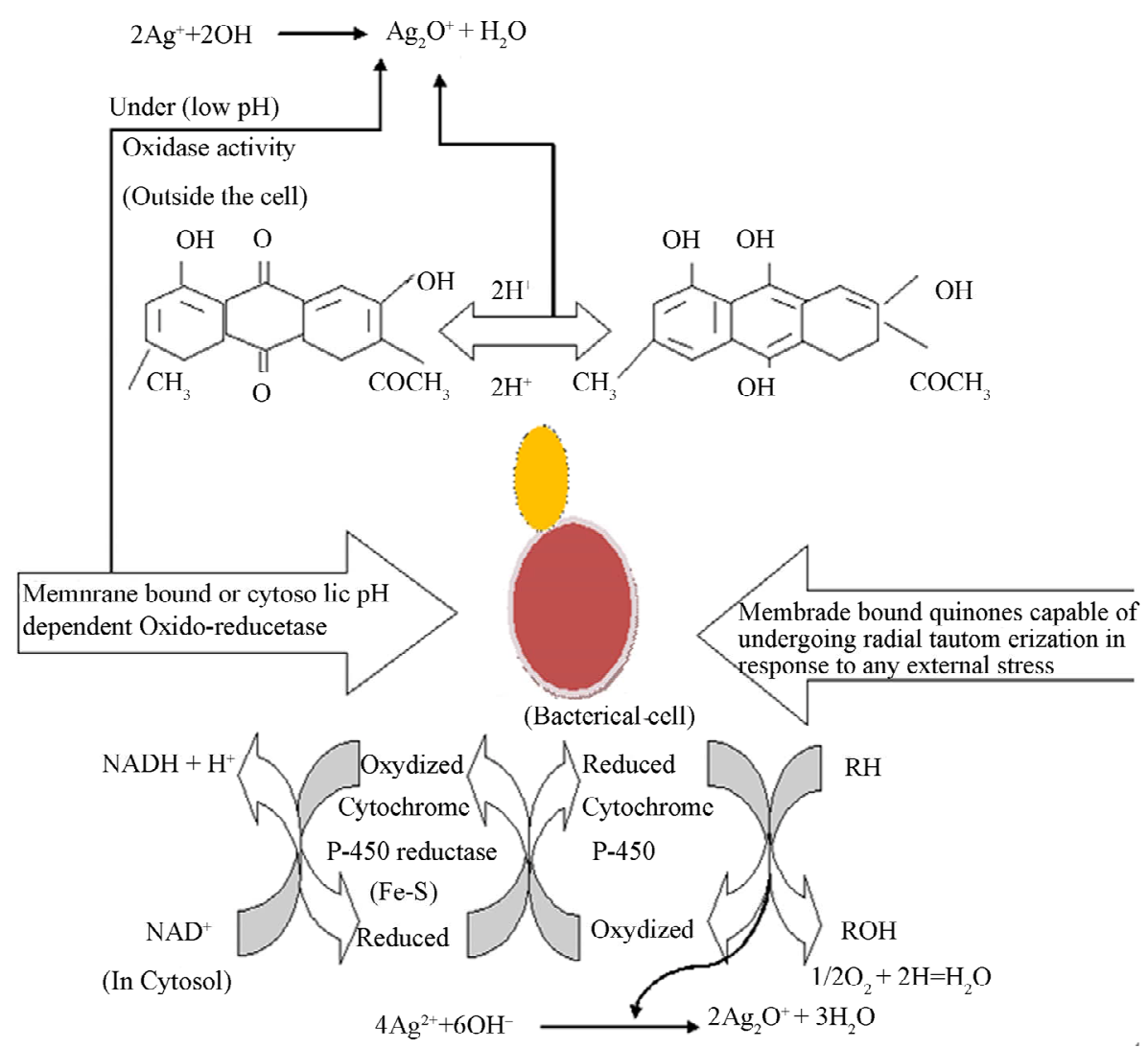

Figure 3. Schematics for the biosynthesis of AgNPs using Bacillus Cereus.

04-0783. The diffraction peaks were found to be broad around their bases indicating that the silver particles are in nanosizes. The peak broadening at half maximum intensity of the X-ray diffraction lines is due to a reduction in crystallite size, flattening and microstrains within the diffracting domains. Scherrer's equation for broadening resulting from a small crystalline size, the mean, effective or apparent dimension of the crystalline composing the powder is,

$$
\mathrm{P}_{\mathrm{hk} 1}=k \lambda / \beta_{1 / 2} \cos \theta,
$$

where $\theta$ is the Bragg angle and $\lambda$ is the $\mathrm{X}$-ray wavelength, $\beta$ is the breadth of the pure diffraction profile in radians on $2 \theta$ scale and $\mathrm{k}$ is a constant approximately equal to unity and related both to the crystalline shape and to the way in which $\beta$ is defined. The best possible value of $\mathrm{k}$ has been estimated as 0.89 . The particle sizes of all the samples in our study have been estimated by using the above Scherer's equation and were found to be $\sim 15 \mathrm{~nm}$ for the strongest peak. TEM technique was employed to visualize the size and shape of the silver nanoparticles formed.

Figure 5(a) and b shows the typical bright-filed TEM images of the synthesised silver nanoparticles. It is observed from this image that the nanoparticles are isolated and are surrounded by a layer of organic matrix at some places, which acts as capping agent for the silver nanoparticles. The difference in size may possibly be due to the fact that the nanoparticles are being formed at different times. Most of the silver nanoparticles are spherical in shape, and are in the range of $10-30 \mathrm{~nm}$ in size which is in close agreement with the particle size calculated

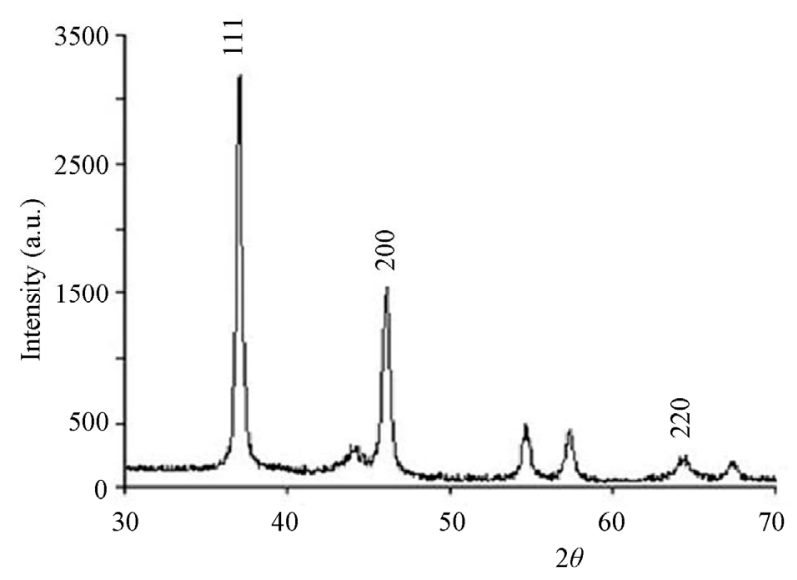

Figure 4. Room temperature $X$-ray diffraction pattern of AgNPs. 


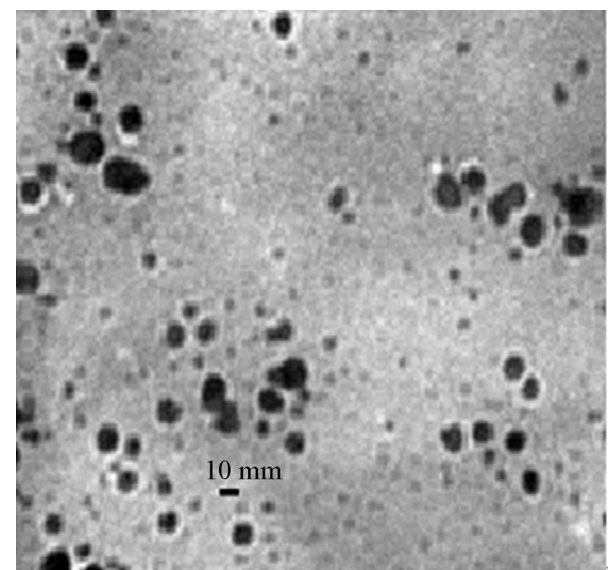

(a)

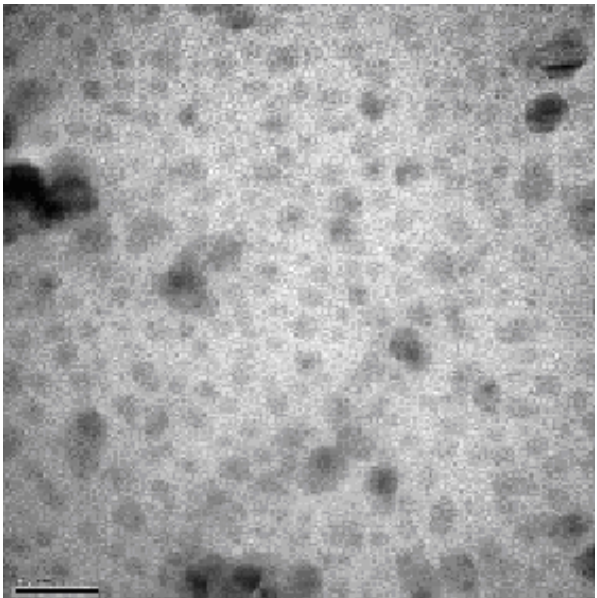

(b)

Figure 5. TEM photographs of AgNPs from Bacillus cereus at different magnifications.

from the XRD profile. A few agglomerated silver nanoparticles were also observed in some places, thereby indicating possible sedimentation at a latter time (after 12 weeks). The TEM image suggests that the particles are polydispersed and are mostly spherical in shape. Selected area electron diffraction (SAED) spots that corresponded to the (from inside to outside of the central ring) [111], [200], [220], [311] and [222] planes of the face-centered cubic (fcc) structure of elemental silver are clearly seen in Figure 6(a). HRTEM image shows (Figure 6(b)) the d spacing of $2.02 \AA$, which matches with the [200] crystallographic plane of AgNPs. Figure 7 shows the Energy Dispersive Absorption Spectroscopy photograph of AgNPs. All the peaks of Ag are observed and are assigned. Peaks for $\mathrm{Cu}$ and $\mathrm{C}$ are from the grid used and the peaks for $\mathrm{S}, \mathrm{P}$ and $\mathrm{N}$ correspond to the protein capping over the AgNPs. It is reported earlier that proteins can bind to nanoparticles either through free amine groups or cysteine residues in the proteins [20] and via

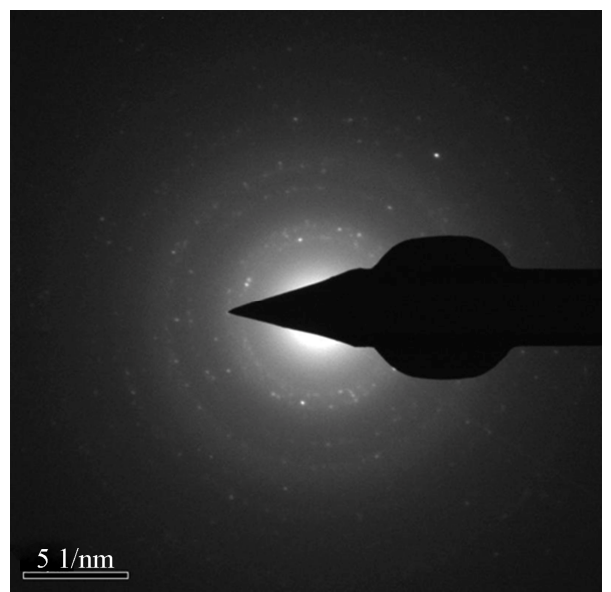

(a)

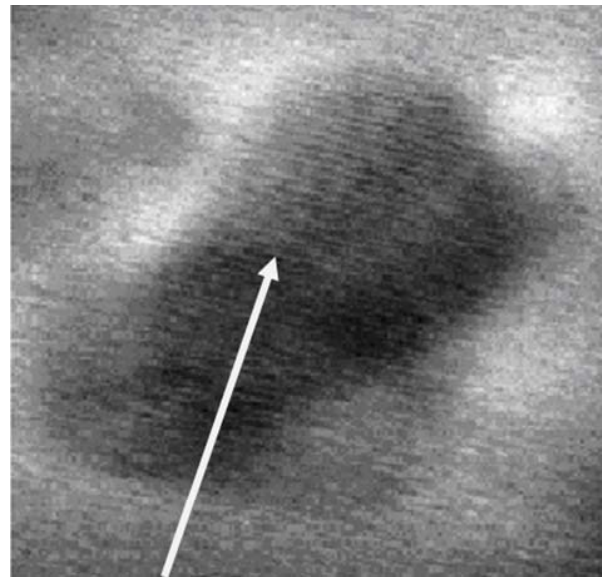

(b)

Figure 6. (a) Selected area diffraction pattern of AgN-Ps; (b) HRTEM image showing characteristics spacing for [200] plane.

the electrostatic attraction of negatively charged carboxylate groups in enzymes present in the cell wall of bacteria [21] and therefore, stabilization of the AgNPs by protein is a possibility. The amide linkages between amino acid residues in proteins give rise to the wellknown signatures in the infrared region of the electromagnetic spectrum and have been shown by the FTIRspectrum [22]. In future, it would be important to understand the biochemical and molecular mechanism of the synthesis of nanoparticles by the cell filtrate in order to achieve better control over size and polydispersity of the nanoparticles.

\subsection{Antibacterial Properties of Bio-Synthesized AgNPs}

The bactericidal effect of AgNPs is well established; however the mechanism is only partially understood. It has been reported that ionic silver strongly interacts with 
Table 1. Data showing zone of inhibition of streptococcus, E. coli and some standard antibiotics in different concentration of AgNPs .

\begin{tabular}{cccccccc}
\hline \multirow{2}{*}{$\begin{array}{c}\text { No of observa- } \\
\text { tions }\end{array}$} & $\begin{array}{c}\text { Concentration of } \\
\text { AgNPs (in ppm) }\end{array}$ & \multicolumn{5}{c}{ Zones of inhibition (diameter, in cm) } \\
\cline { 3 - 7 } & & E.Coli & Streptococcus & Chloremphenicol & Wymox & Erythromycin & Oxytetracyclin \\
1 & 100 & $1-1.7$ & $1-2$ & $1-2.1$ & $1-1.75$ & $1-1.7$ & $1-2.4$ \\
2 & 50 & $1-1.5$ & $1-1.7$ & $1-1.3$ & $1-1.5$ & $1-1.2$ & $1-1.6$ \\
3 & 20 & $1-1.2$ & $1-1.6$ & $1-1.4$ & $1-1.4$ & $1-1.6$ & $1-1.20$ \\
\hline
\end{tabular}

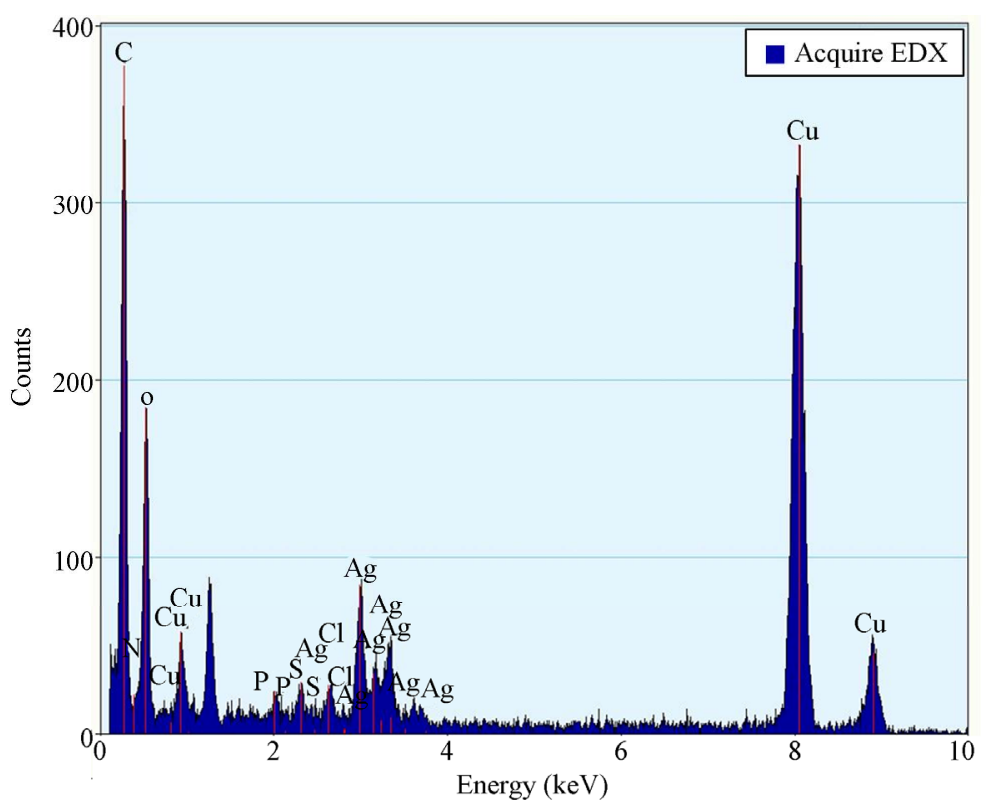

Figure 7. Energy Dispersive Absorption Spectroscopy photograph of AgNPs.

thiol group of vital enzymes and inactivates them [23, 24]. Experimental evidence suggests that DNA loses its replication ability once the bacteria have been treated with silver ions [25]. The antibacterial effect of nanoparticles can be attributed to their stability in the medium as a colloid, which modulates the phosphotyrosine profile of the bacterial proteins and arrests bacterial growth. The effect is dose dependent and is independent of acquisition of resistance by the bacteria against antibiotics. Antibacterial effect of the synthesized AgNPs was tested with a gram negative and gram positive bacteria $E$. Coli and Streptococcus in varying strength of nanoparticles colloid. It was observed that the lowest concentration up to $50 \mathrm{ppm}$ was sufficient to inhibit bacterial growth. Zones of inhibition were measured after $24-48 \mathrm{hrs}$ of incubation (Table 1). Zones of inhibition were almost of circular shape therefore the inhibitory zones were measured in diameter $(\mathrm{cm})$. The comparative stability of discs containing Wymox, Chloremphenicol, Ampicilin, Oxytetracycline was also made which exhibited reduced growth of microbes. It was observed that the zone of inhibition formed due to silver nanoparticles was more prominent as compared with the inhibition zones of the antibiotics.

\section{Conclusions}

In this study, extracellular synthesis of AgNPs has been shown from silver-resistant Bacillus sp. isolated from the riverine belt of Gangetic Plain of India. XRD analysis showed that the nanoparticles were crystalline and metallic in nature. HRTEM analysis showed that most of the particles were spherical in shape with size $\sim 15 \mathrm{~nm}$. This extracellular bacterial synthesis of AgNPs has many advantages over the chemically derived nanoparticles and might be an excellent means of developing an ecologically friendly protocol.

\section{Acknowledgements}

The authors wish to acknowledge University Grants Commission, New Delhi, India for the financial support under the major research project scheme. 


\section{REFERENCES}

[1] P. K. Stoimenov, R. L. Klinger, G. L. Marchin and K. J. Klabunde, "Metal Oxide Nanoparticles as Bactericidal Agents." Langmuir, Vol. 18, 2002, pp. 6679-6686. doi:10.1021/la0202374

[2] R. M. Streicher, M. Schmidt, S. Fiorito, "Nanosurfaces and Nanostructures for Artificial Orthopedic Implants," Nanomedicine, Vol. 2, 2007, pp. 861-874. doi:10.2217/17435889.2.6.861

[3] R. Langer, "Perspective: Drug Delivery-Drug on Target," Science, Vol. 293, No. 5527, 2001, pp. 58-59. doi:10.1126/science.1063273

[4] A. Ahmad, S. Senapati, R. Kumar and M. Sastry, "Extracellular Biosynthesis of Monodisperse Gold Nanoparticles by a Novel Extremophilic Actinomycete, Thermomonospora sp," Langmuir, Vol. 19, 2003, pp. 3550-3553. doi:10.1021/la0267721

[5] B. Nair and T. Pradeep, "Coalescence of Nanoclusters and the Formation of Submicron Crystallites Assisted by Lactobacillus Strains," American Chemical Social, Vol. 2, 2002, pp. 293-298.

[6] B. L. V. Prasad, S. K. Arumugam, T. Bala and M. Sastry, "Solvent Adaptable Silver Nanoparticles," Langmuir, Vol. 21, No. 3, 2005, pp. 822-826. doi:10.1021/la047707+

[7] A. Kumar, S. Mandal, P. R. SelvaKannan, R. Pasricha, A. B. Mandale and M. Sastry, "Investigation into the Interaction between Surface Bound Alkylamines and Gold Nanoparticles," Langmuir, Vol. 19, No. 15, 2003, pp. 6277-6282. doi:10.1021/la034209c

[8] K. A. Bogle, S. D. Dhole and V. N Bhoraskar, "Silver Nanoparticles: Synthesis and Size Control by Electron Irradiation," Nanotech, Vol. 17, 2006, pp. 3204-3208. doi:10.1088/0957-4484/17/13/021

[9] J. C. Lin, W. C Tsai and W.S Lee, "The Improved Electrical Contact between a Metal and Porous Silican by Deposition Using a Supercritical Fluid," Nanotech, Vol. 17, 2006, pp. 2968-2971. doi:10.1088/0957-4484/17/12/024

[10] L. Balogh, D. R Swanson, D. R Tomalia, G. L Hagnauer and A. T. McManus, "Dendrimer-Silver Complexes and Nanocomposites as Antimicrobial Agents," Nanoletters, Vol. 1, 2001, doi:10.1021/n1005502p

[11] X. Shi, T. R. Ganser, K. San, L. P. Balogh and J. R. Baker Jr, "Characterization of Crystalline DendrimerStabilized Gold Nanoparticles," Nanotechnology, Vol. 17, 2006, pp. 1072-1076. doi:10.1088/0957-4484/17/4/038

[12] C. N. Lok, "Proteomic Analysis of the Mode of Antibacterial Action of Silver Nanoparticles," Journal Proteome Research, Vol. 5, 2005, pp. 916-924. doi:10.1021/pr0504079

[13] S. Pal., Y. Tak, and J. M. Song, "Does the Antibacterial Activity of Silver Nanoparticles Depend on the Shape of the Nanoparticle? A Study of the Gram-Negative Bacterium Escherichia Coli," Applied Environment, Microbi- ology, Vol. 73, 2007, pp. 1712-1720.

doi:10.1128/AEM.02218-06

[14] C. T. Dameron, R. N. Reese, R. K. Mehra, A. R. Katari, P. J. Carroll, M. L. Steigerwald, L. E. Brus and D. R., "Winge. Biosynthesis of Cadmium Sulphide Quantum Semiconductor Crystallites," Nature, Vol. 338, 1989, pp. 596-597. doi:10.1038/338596a0

[15] J. M. Boyce, "Reevaluation of the Ability of the Standardized Disk Diffusion Test to Detect Methicillin Resistant Strains of Staphylococcus Aureus," Journal of Clinical Microbiology, Vol. 19, 1984, pp. 813-817.

[16] W. Lawerence, A. L Barry., R. Otoole and J. Sherris, "Reliability of the Kirby-Bauer Disc Diffusion Method for Selecting Methicilin Resistant Strains of Staphylococcus Aureus," Applied Micrology, Vol. 24, 1972, pp. 240-247.

[17] A. K. Jha, Kamlesh Prasad and K. Prasad, "A Green Low Cost Biosynthesis of $\mathrm{Sb}_{2} \mathrm{O}_{3}$ Nanoparticles," Biochemical English Journal, Vol. 43, No. 3, 2009, pp. 303-306. doi:10.1016/j.bej.2008.10.016

[18] A. Gole, C. Dash, V. Ramachandran, S. R. Sainkar, A. B. Mandale, M. Rao and M. Sastry, "Pepsin-Gold Colloid Conjugates: Preparation, Characterization, and Enzymatic Activity," Langmuir, Vol. 17, No. 5, 2001, pp. 1674-1679. doi:10.1021/la001164w

[19] S. Mandal, S. Phadtare and M. Sastry, "Interfacing Biology with Nanoparticles," Current Applied Physics, Vol. 5, No. 2, 2005, pp. 118-127. doi:10.1016/j.cap.2004.06.006

[20] M. Sastry, A. Ahmad, M. IslamKhan and R. Kumar, "Biological Synthesis of Metal Nanoparticles Using Fungi and Actinomycetes," Current Science, Vol. 85, No. 2, 2003, pp. 162-170.

[21] N. Vigneshwaran, N. M. Ashtaputre, P. V. Varadarajan, R. P. Nachane, K. M. Paralikar and R. H. Balasubramanya, "Biological Synthesis of Silver Nanoparticles Using the Fungus Aspergillus Flavus," Materials Letter, Vol. 61, 2007, pp. 1413-1418. doi:10.1016/j.matlet.2006.07.042

[22] Y. Matsumura, K Yoshikata, S. Kunisaki, and T. Tsuchido, "Mode of Bactericidal Action of Silver Zeolite and Its Comparison with That of Silver Nitrate," Applied Environment Microbiology, Vol. 69, No. 7, 2003, pp. 4278-4281.

[23] A. Gupta, M. Maynes and S. Silver, "Effects of Halides on Plasmid Mediated Silver Resistance in Escherichia Coli," Applied Environment Micrology, Vol.64, 1998, pp. 5042-5045.

[24] Q. L. Feng, J. Wu, G. Q. Chen, F. Z. Cui, T. N. Kim and J. O. Kim, "A Mechanistic Study of the Antibacterial Effect of Silver Ions on Escherichia Coli and Staphylococcus aureus," Journal of Biomedical Materials Research, Vol. 52, No. 4, 2000, pp. 662-668. doi:10.1002/1097-4636(20001215)52:4<662::AID-JBM10>3. $0 . \mathrm{CO} ; 2-3$

[25] M. Singh, S. Singh, S. Prasad and I. S. Gambhir, "NanoTechnology in Medicine and Antibacterial Effect of Silver Nanoparticles," Digest Journal of Nanomaterials and Biostrstructures, Vol. 3, 2008, pp. 115-122. 